\title{
Evaluating temporal stability of the New Zealand quasigeoid following the 2016 Kaikoura earthquake using satellite radar remote sensing
}

\author{
J.C. McCubbine ${ }^{\oplus},{ }^{1}$ V. Stagpoole ${ }^{\oplus}, 2$ F. Caratori Tontini ${ }^{\oplus}, 2$ W.E. Featherstone ${ }^{\oplus}, 3$ \\ M.C. Garthwaite ${ }^{\oplus}, 1$ N.J. Brown ${ }^{\odot, 1}$ M.J. Amos ${ }^{\oplus}, 4$ Y. Fukuda ${ }^{\odot}, 5$ T. Kazama ${ }^{\oplus, 5}$ \\ H. Takiguchi ${ }^{6}$ and J. Nishijima ${ }^{7}$ \\ ${ }^{1}$ National Geodesy Section, Positioning and Community Safety Division, Geoscience Australia, GPO Box 378, Canberra, ACT 2601, Australia. \\ E-mail: jack.mccubbine@ga.gov.au \\ ${ }^{2}$ GNS Science, 1 Fairway Dr, Avalon, Lower Hutt 5011, New Zealand \\ ${ }^{3}$ School of Earth and Planetary Sciences, Curtin University of Technology, GPO Box U1987, Perth, WA 6845, Australia \\ ${ }^{4}$ Land Information New Zealand, PO Box 5501, Wellington 6145, New Zealand \\ ${ }^{5}$ Department of Geophysics, Graduate School of Science, Kyoto University, Yoshida-honmachi, Sakyo-ku, Kyoto 606-8501, Japan \\ ${ }^{6}$ JAXA: Japan Aerospace Exploration Agency, Ochanomizu sola city, 4-6 Kandasurugadai, Chiyoda-ku, Tokyo 101-8008, Japan \\ ${ }^{7}$ Department of Earth Resources Engineering, Graduate School of Engineering, Kyushu University, 744 Motooka Nishi-ku, Fukuoka 819-0395, Japan
}

Accepted 2019 November 19. Received 2019 November 18; in original form 2019 August 19

\begin{abstract}
SUMMAR Y
Quasigeoid models can be determined from surface gravity anomalies, so are sensitive to changes in the shape of the topography as well as changes in gravity. Here we present results of forward modelling gravity/quasigeoid changes from synthetic aperture radar data following the $2016 M_{\mathrm{w}} 7.8$ Kaikōura earthquake with land uplift of up to $10 \mathrm{~m}$. We assess the impact of the topographic deformation on the reference surface of the New Zealand vertical datum in lieu of costly field gravity field measurements. The most significant modelled gravity and quasigeoid changes are $-2.9 \mathrm{mGal}$ and 5-7 $\mathrm{mm}$, respectively. We compare our forward modelled gravity signal to terrestrial gravity observation data and show that differences between the data sets have a standard deviation of $\pm 0.1 \mathrm{mGal}$. The largest modelled change in the quasigeoid is an order of magnitude smaller than the $57.7 \mathrm{~mm}$ estimated precision of the most recently computed NZGeoid model over the Kaikoura region. Modelled quasigeoid changes implied by this particular deformation event are not statistically significant with respect to estimated precision of the New Zealand quasigeoid model.
\end{abstract}

Key words: Geopotential theory; Time variable gravity; New Zealand.

\section{INTRODUCTION}

In tectonically active regions, the shape of the Earth's topographic surface can change significantly over short time periods. Changes in the topography have a direct effect on gravity anomalies and therefore quasigeoid models derived from them. On the $14^{\text {th }}$ of November 2016, a $7.8 M_{\mathrm{w}}$ earthquake occurred below the Kaikōura region, in the northeast of New Zealand's South Island. This earthquake was the most powerful experienced in New Zealand for more than 150 yr (Hamling et al. 2017). It caused the Earth's surface to uplift by up to $10 \mathrm{~m}$ (Fig. 1a), occurring over two distinct seismic domains and on multiple fault lines (Hamling et al. 2017; Gusman et al. 2018).

Following the study by Chen et al. (2007) on the SumatraAndaman earthquake, we initially attempted to assess the change in the gravity field over the Kaikōura region by analysing GRACE
(Tapley et al. 2004) data. However, the Sumatra-Andaman earthquake had magnitude of $9.3 M_{\mathrm{w}}$ and deformation extending over $1800 \mathrm{~km}$. In contrast, the 2016 Kaikōura earthquake was smaller in magnitude $\left(7.8 M_{\mathrm{w}}\right.$ ) and more localized, with topographic deformation extending over a region of less than $100 \mathrm{~km}$. This is shorter than the wavelengths that can be reliably resolved by GRACE spherical harmonic and mass concentration solutions. For this reason, we were unable to detect any discernible change in the gravity signal provided by GRACE data. Instead, we forward-model the change in the quasigeoid from topographic changes measured by interferometric satellite radar altimetry.

On-shore, short wavelength $(<100 \mathrm{~km})$ features of the New Zealand regional quasigeoid model were determined from terrestrial and airborne gravity anomalies ( $c f$. McCubbine et al. 2018a). The acquisition of terrestrial and airborne gravity data is costly and time consuming, so an alternative becomes attractive. Various 
(a)

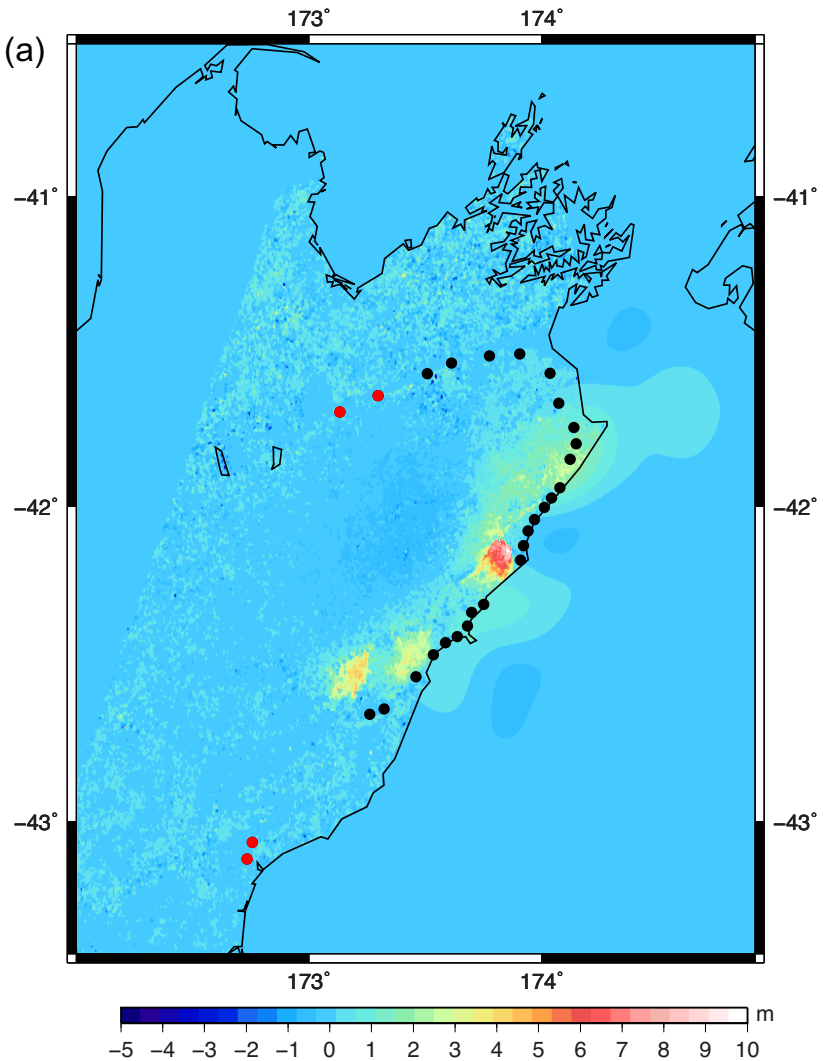

(c)

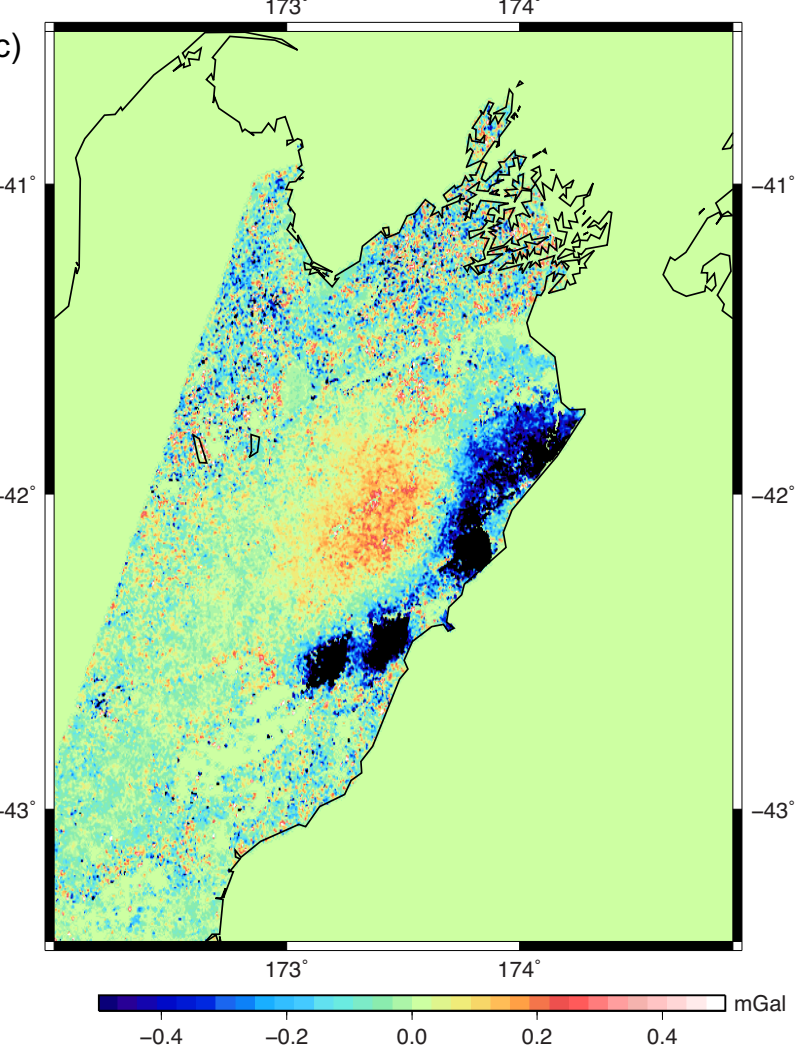

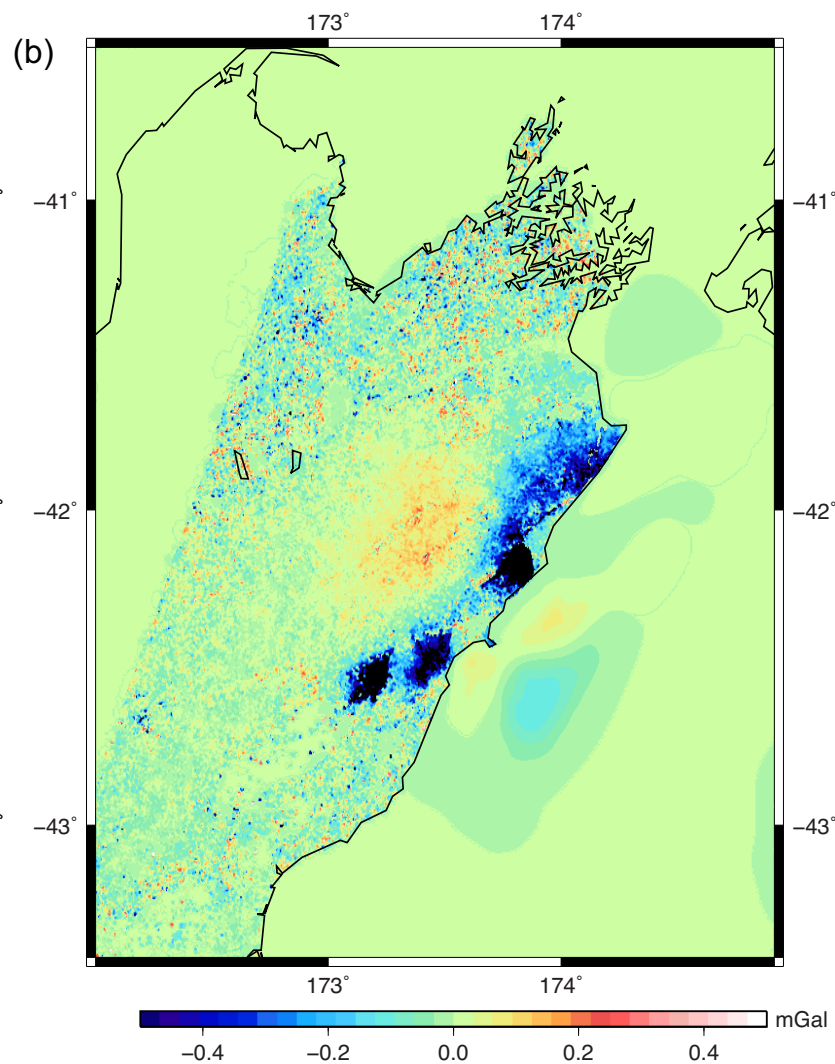

(d)

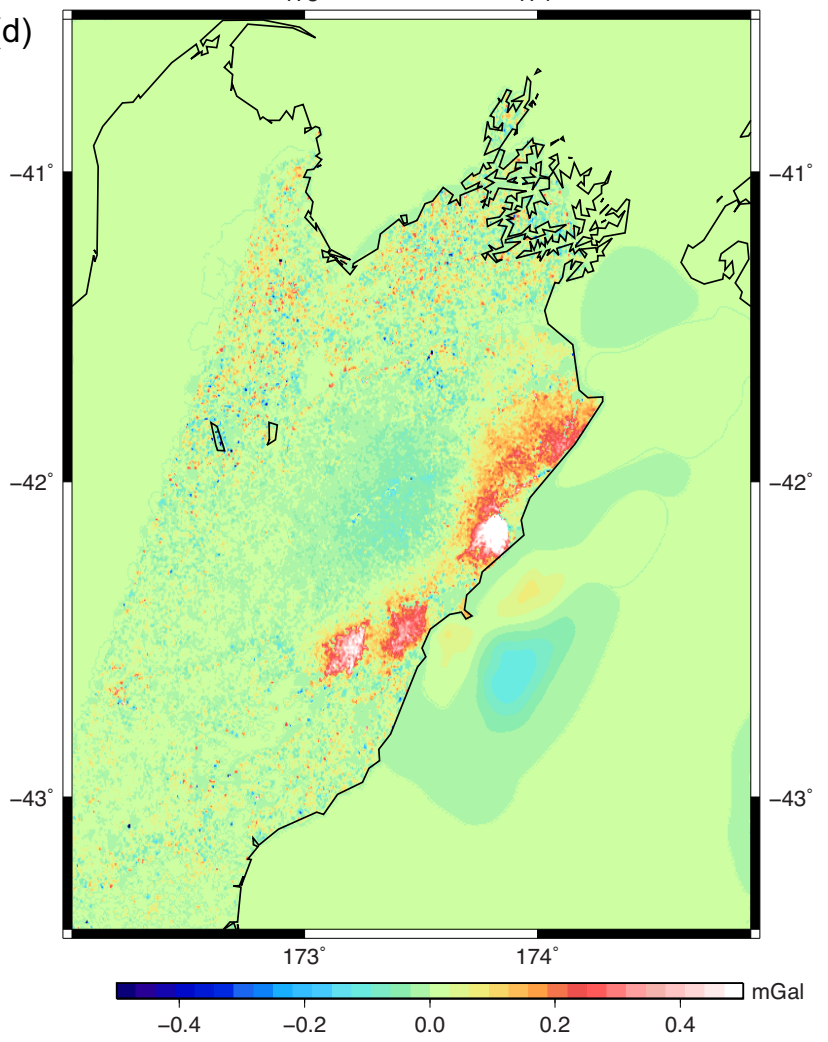

Figure 1. (a) Vertical deformation following the Kaikōura earthquake determined from SAR. [min: -5.24 , max: 10.04, mean: 0.07, std: 0.28] m. Red and black dots show the ground truth and land gravity profile (b) Gravity change synthesized from the vertical deformation using free air gradients and Newtonian prism integration [min: -2.9 , max: 1.6, mean: $-0.0(1)$, std: 0.1 ] mGal. (c) Gravity change synthesized from the vertical deformation due to free air gradients [min: -3.1 , max: 1.6, mean: $-0.0(2)$, std: 0.1$]$ mGal. (d) Gravity change synthesized from the vertical deformation due to Newtonian prism integration [min: -0.7 , max: 1.1, mean:0.0(07), std: 0.0(51)] mGal. 
forward-modelling formulas exist to determine the gravity field resulting from a body with a known volume and density (e.g. Nagy 1966; Zhou et al. 1990; Li \& Sideris 1994; Nagy et al. 2000). These formulas are frequently used to approximate gravity signals that are under sampled by gravity field measurements by forward modelling residual terrain with constant density (e.g. Forsberg 1984, 1993; Hirt et al. 2010; Rexer et al. 2018). We propose that localized changes in the shape of terrain can be considered in the same regard, in effect modelling residual terrain in the time domain rather than the space domain.

Synthetic aperture radar (SAR) data can be used to measure Earth surface displacements over large areas via either interferometric SAR (InSAR) processing or by measuring pixel offset tracking of SAR amplitude images. InSAR can resolve centimetric surface displacements in the radar-looking direction, which is sensitive to vertical surface movements if the radar incidence angle is steep. Indeed, InSAR was able to capture the surface deformation field of many recent large thrust earthquakes (e.g. Lindsey et al. 2015; Hamling et al. 2017; Garcia \& Funning 2018). Furthermore, if InSAR data from both ascending and descending orbital viewing geometries is available, the vertical displacement can be derived. However, the InSAR technique suffers from signal decorrelation that can reduce its effectiveness in resolving a complete picture of the deformation field (e.g. Garcia \& Funning 2018).

Pixel offset tracking of SAR amplitude images involves measuring offsets in the range and azimuth of the radar images by performing cross-correlation across image patches and measuring the position of peak correlation. Since the range direction of the radar viewing geometry is slanted between the ground and the satellite, offsets in this direction are sensitive to vertical surface displacements. Hamling et al. (2017) used this approach to derive vertical and horizontal surface displacement maps for the 2016 Kaikōura earthquake. Pixel offset tracking has the advantage that it does not suffer from decorrelation like InSAR and can therefore map the surface deformation field more completely. However, it has the drawback that it is less precise than InSAR, with surface displacements at the scale of the image pixel size (e.g. metre-scale) only being resolvable. It is therefore only viable for measuring large-magnitude (metre-scale) surface deformation.

In this investigation, we explore the use of topographic elevation changes derived from Sentinel-1 SAR data (Torres et al. 2012) to estimate an equivalent 'snap shot' of changes in the surface gravity and the quasigeoid, following the 2016 Kaikoura earthquake. We also present a method to model variations in the estimated surface gravity and quasigeoid within the paradigm of a simplistic formulation due to changes in the vertical gravity gradients and topographic bulk density. From a practical standpoint, we hope to establish the potential impact of the deformation event on the quasigeoid in lieu of costly gravity surveys over and around the affected region.

The 2016 Kaikoura earthquake may also have caused a redistribution of masses below the topographic surface, which would also cause a change in the gravity signal at the Earth's surface. However, we do not have access to data that can be used to determine these mass-density changes across the whole region directly. Instead, we only consider changes in gravity anomalies produced by the changes in surface elevation. Forward gravity modelling SAR data approximates the gravitational response of the earthquake purely by the addition (uplift) and/or removal (subsidence) of topographic masses at the Earth's surface. For this reason, the forward modelling results we present are only suitable as an initial assessment. To evaluate the integrity of our forward-modelled gravity change, we compare it to a profile of gravity observations through the area of deformation collected before and after the earthquake.

Broadly speaking, but not definitively (see, e.g. Sansò \& Sideris 2013), there can be two approaches to quasigeoid modelling: one where Molodensky gravity anomalies after application of the G1 terms (often approximated by Faye gravity anomaly, being the free air gravity anomaly plus the planar terrain correction (e.g. McCubbine et al. 2018c) are Stokes-integrated; the other also includes Stokesian integration but the topographic effects on gravity are removed using forward modelling beforehand and later restored in terms of gravitational potential to the quasigeoid. Least-squares collocation can also be used, but we have not used it here.

To assess the possible change in the quasigeoid with respect to differences between the two theoretical approaches, we experiment with (i) forward modelling of the gravity change from the changed topography as measured by SAR, then Stokes-integrate this using the same parameter choices as used for NZGeoid2017 (McCubbine et al. 2018b) and (ii) determining the change in gravitational potential purely from forward gravity modelling, then converting this to quasigeoid changes via Bruns's formula. In the latter case, both forward modelling approaches (gravitational and potential) use the right-rectangular prism method of Nagy et al. (2000).

\section{FORWARD MODELLING THE GRAVITATIONAL SIGNAL}

\subsection{Modelling the change of gravity at the Earth's surface}

We have forward modelled the change in surface gravity by the addition and removal of topographic/bathymetric masses at the surface of the Earth's crust due to the change in topography/bathymetry caused by the earthquake, with assumed-constant density and gravity gradients over the whole region. For this idealized model, any change in the surface gravity $(\mathrm{D} g$ ) can be approximated by the linear free air gravity gradient, $\frac{\mathrm{dg}}{\mathrm{d} h}$ and Newtonian integration of topographic mass changes, denoted $\Delta g_{\text {Topo }}(\rho)$.

$\left.\mathrm{D} g \approx \Delta H\right|_{\text {onshore }} \frac{\mathrm{d} g}{\mathrm{~d} h}+\Delta g_{\text {Topo }}(\rho)$.

Denoting points above the datum level as 'onshore' and everywhere else as 'offshore', $\left.\Delta H\right|_{\text {onshore }}$ is the change in surface elevation onshore only.

To implement the forward model, we make use of published topographic and bathymetric height change data for the 2016 Kaikoura earthquake derived from Sentinel-1 SAR imagery onshore (Hamling et al. 2017) and GPS and tsunami waveform inversion offshore (Gusman et al. 2018). These data cover the region where surface deformation has occurred (Fig. 1a). Onshore, there are isolated ( $\sim 10 \mathrm{~km}$ wavelength) elevation changes of up to $10 \mathrm{~m}$ in magnitude and broader (approximately $50 \mathrm{~km}$ wavelength) changes of up to $2 \mathrm{~m}$ in magnitude. Offshore, the features of the deformation field are longer wavelength and have a maximum of around $2 \mathrm{~m}$ and minimum of $-1 \mathrm{~m}$. The largest SAR-observed change in height was $+10.04 \mathrm{~m}$, which is located onshore at $42.13^{\circ} \mathrm{S}$ and $173.83^{\circ} \mathrm{E}$.

Fig. 1(b) shows the forward modelled gravity changes using eq. (1), where $\Delta g_{\text {Topo }}(\rho)$ has been computed at the surface of the 'deformed' Earth using the Nagy (1966) right-rectangular prism formula, where the prisms are described by the cells of the vertical deformation model. We have taken $\rho=2670 \mathrm{~kg} \mathrm{~m}^{-3}$ as the topographic bulk density onshore and $\rho=1670 \mathrm{~kg} \mathrm{M}^{-3}$ as the density offshore. The differing density value offshore accounts for the displacement of water with an assumed density of 1000 


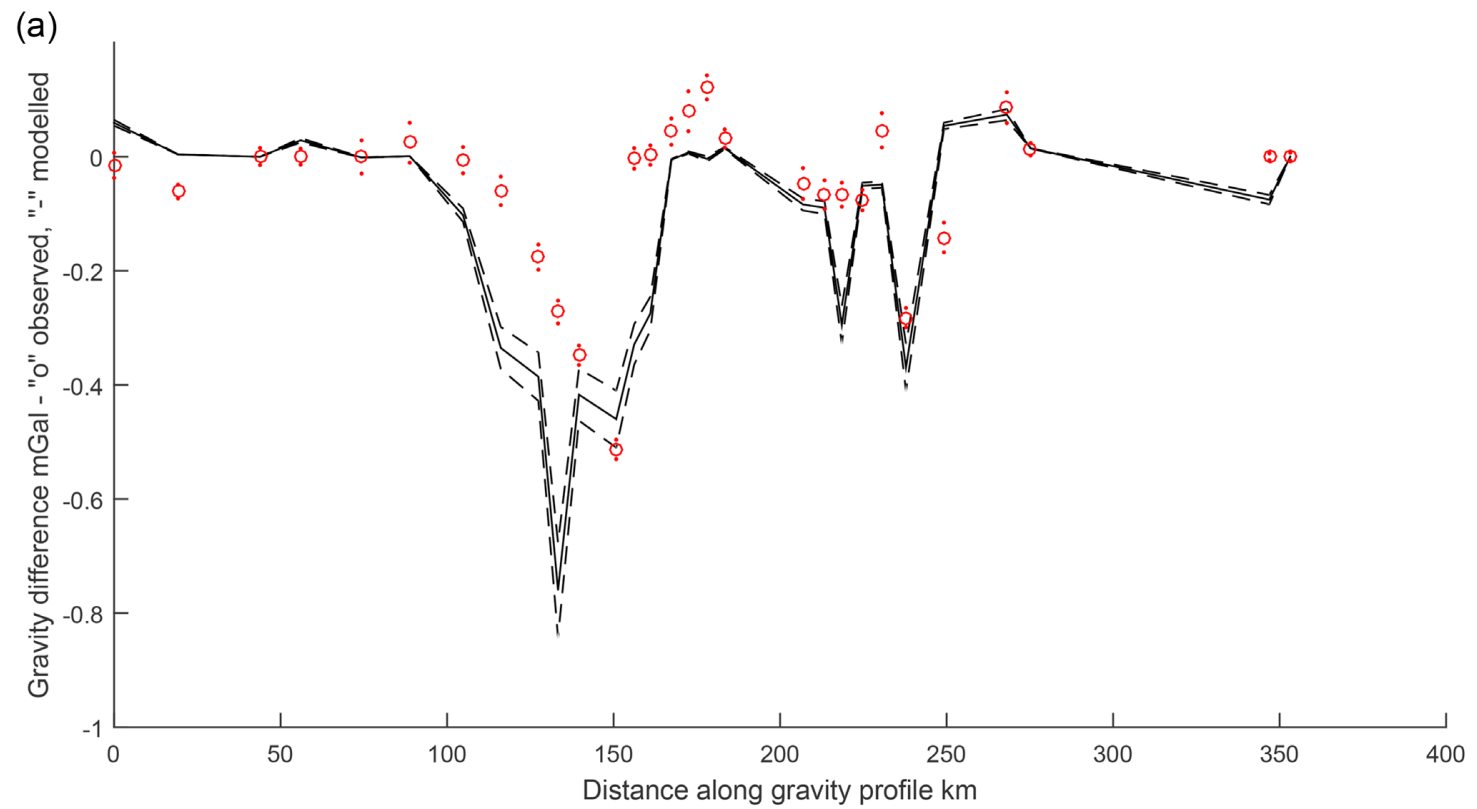

(b)

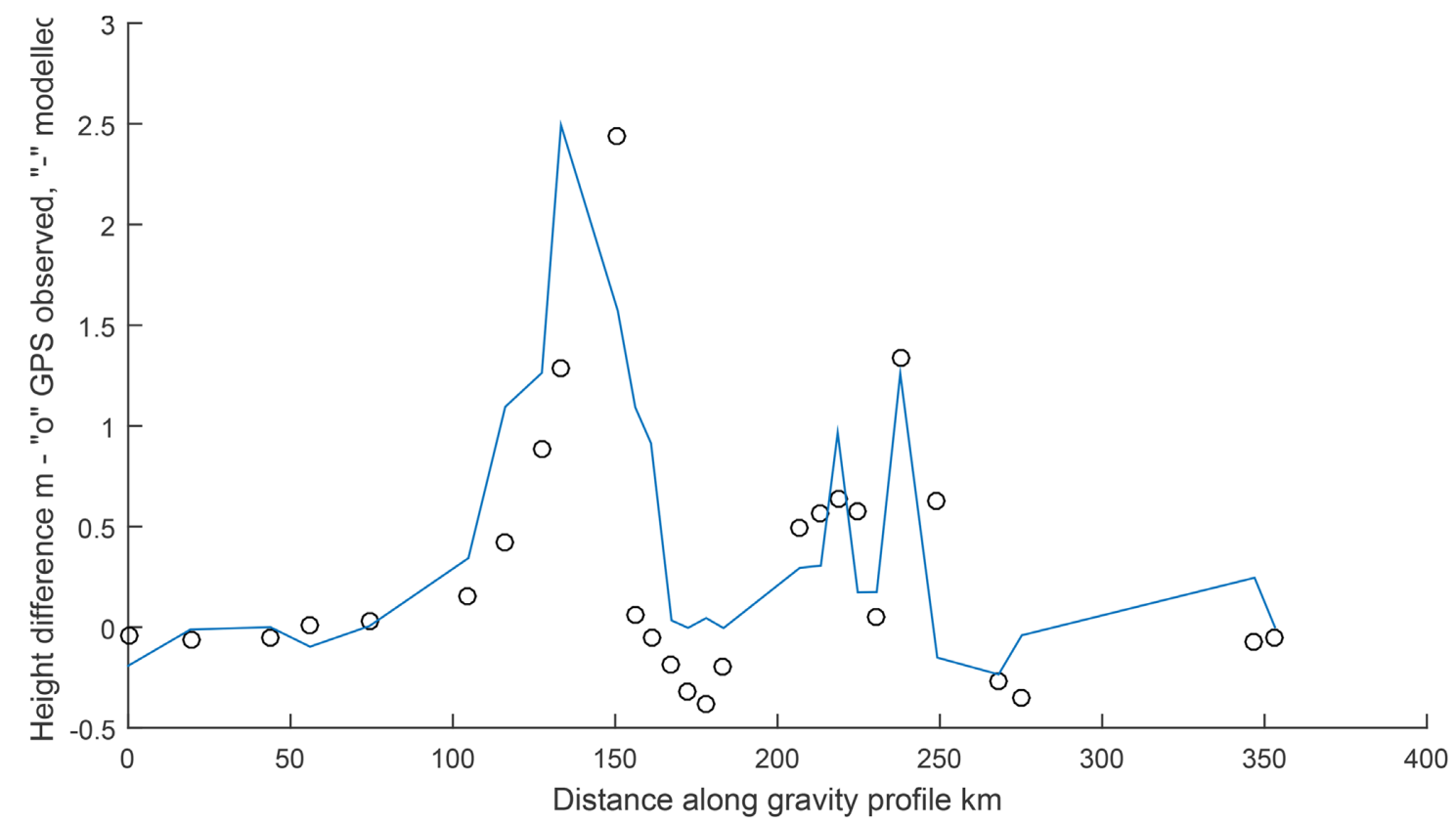

Figure 2. (a) Dg(obs) shown as circles with the standard deviation of the residuals indicated with dots, $\mathrm{D} g$ forward modelled gravity changes shown as solid lines, along ground truth profile. Statistics of differences: [min: -0.5 max: 0.2 mean: $-0.0(8)$ STD: 0.1(4)] mGal (b) GPS observed height changes, shown as circles, and SAR modelled height changes, shown as the solid line, along ground truth profile. Statistics of differences: [min: -0.87 max: 1.21 mean: 0.15 STD: $0.50] \mathrm{m}$.

$\mathrm{kg} \mathrm{M}^{-3}$ by rock with density $2670 \mathrm{~kg} \mathrm{~m}^{-3}$. The 8 -m-resolution New Zealand DEM (NZ 8 m Digital Elevation Model, 2012, from https://data.linz.govt.nz) was block averaged to $15^{\prime \prime}$ ( $\left.\sim 500 \mathrm{~m}\right)$ using GMT (Wessel et al. 2013), commensurate with the deformation observations, and was used to establish $H$ onshore and the bathymetric model Etopo1 (Amante \& Eakins 2009) was used offshore. We assumed during this process that the reference datum for the New Zealand DEM and Etopo 1 coincide; differences are undetectable at the supplied $1 \mathrm{~m}$ integer rounding of the Etopol depths.

The Newtonian integration required the computation of the gravitational effect and sum of all 490000 right-rectangular prisms for each point of the grid. To accomplish this we used our own public domain Matlab code [available here (2019); https://au.mathworks.com/matlabcentral/fileexchange/57 349-nagyprism-x1-x2-y1-y2-h-rho]. No cap on the integration radius was required to alleviate the computational burden, due to the small $(<100 \mathrm{~km})$ size of the area under investigation. The derived surface gravity changes have a minimum of $-2.9 \mathrm{mGal}$ and a maximum of $+1.6 \mathrm{mGal}$ (Fig. 1b). The changes are caused predominately by variations in elevation related to the corresponding free air gravity gradient ( $c f$. eq. 1). The separate contributions of the free air effect $\left(\left.\Delta H\right|_{\text {onshore }} \frac{\mathrm{d} g}{\mathrm{~d} h}\right)$ and topographic effect $\left[\Delta g_{\text {Topo }}(\rho)\right]$ 


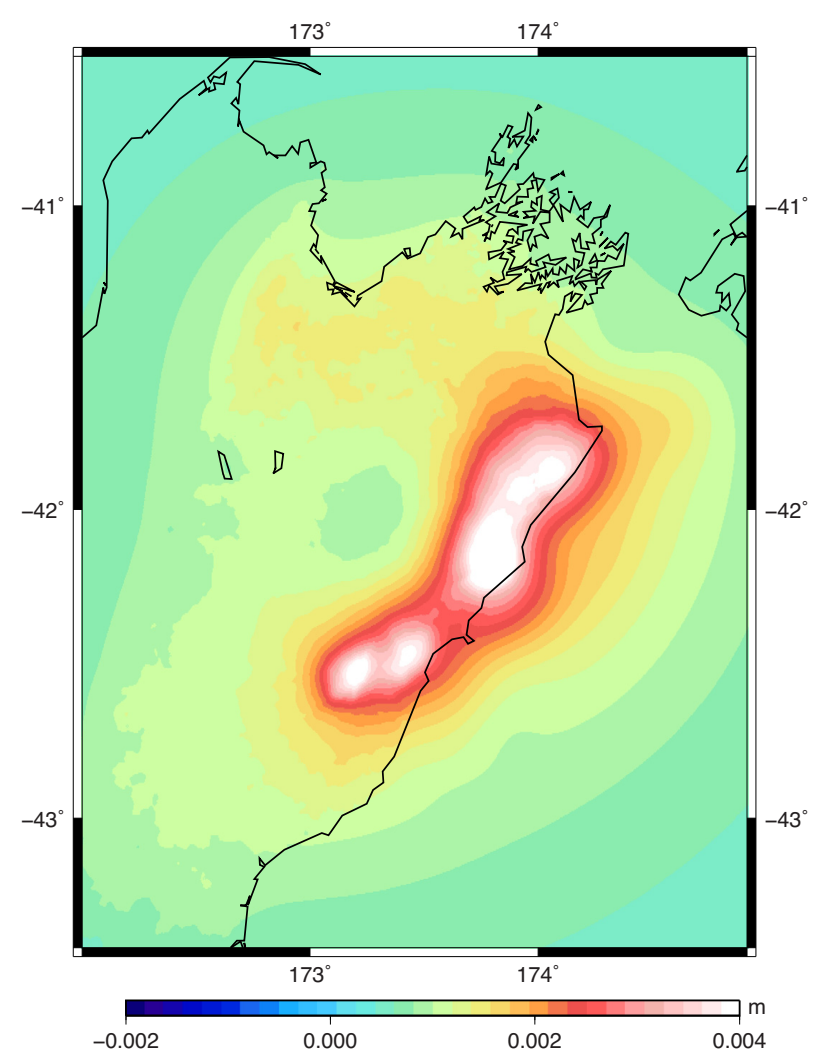

Figure 3. Change in the quasigeoid due to the vertical deformation caused by the Kaikōura earthquake synthesized by Nagy et al. (2000) prism formula for potential. [min: $0(.4)$, max: 6 , mean: 1 , std: $0 .(6)] \mathrm{mm}$.

are shown in Figs 1(c) and (d). The minimum is located at the point $\left(42.13^{\circ} \mathrm{S}, 173.83^{\circ} \mathrm{E}\right)$ where the largest amount of vertical deformation occurred $(+10.04 \mathrm{~m})$.

\subsection{Uncertainty in the forward-modelled gravity signal}

The choice of $0.3086 \mathrm{mGal} \mathrm{m}^{-1}$ linear vertical free air gradient is based on a spherical Earth approximation and the topographic bulk density of $2670 \mathrm{~kg} \mathrm{~m}^{-3}$ is based on the most commonly used value in Bouguer reductions. They may not be strictly representative of the Kaikoura region, although the density estimate agrees closely with published data for New Zealand rock densities over the region (Hatherton \& Leopard 1964). We have investigated how the modelled surface gravity changes might vary due to feasible variations in the, assumed, regionally constant linear free air gravity gradient and rock bulk density values by considering the first-order Taylor series expansion of eq. (1) around these terms. We consider a range of possible gravity gradients and densities by modelling them as Gaussian-distributed values with standard deviations $\sigma_{\mathrm{FA}}$ and $\sigma_{\rho}$, respectively. Eq. (2) gives a propagation formula due to both of these terms.

$\sigma(\mathrm{D} g)= \pm \sqrt{\left(\Delta H \sigma_{\mathrm{FA}}\right)^{2}+\left[\sigma_{\rho} \frac{\Delta g_{\mathrm{Topo}}(\rho)}{\rho}\right]^{2}}$.

In Fig. 2(b), we have taken $\sigma_{\mathrm{FA}}= \pm 0.034 \mathrm{mGal} \mathrm{m}^{-1}$ and $\sigma_{\rho}=$ $\pm 340 \mathrm{~kg} \mathrm{~m}^{-3}$. The maximum is $0.3(7) \mathrm{mGal}$, again at the point where there has been the most elevation change. With these standard deviation values, the results given by eq. (2) correspond to the standard deviation in the surface gravity change due to (i) the density varying up to $\pm 1000 \mathrm{~kg} \mathrm{~m}^{-3}$ (i.e. so that we capture the effect of a range of rock types from loose sediments with $\rho \approx 2300 \mathrm{kgm}^{-3}$ to mantle density with $\rho \approx 3300 \mathrm{~kg} \mathrm{~m}^{-3}$ ) and (ii) the free air gradient varying up to $\pm 0.1 \mathrm{mGal} \mathrm{m}^{-1}$ within the three sigma levels of the respective distributions. These capture generous bounds on the possible surface gravity values within the paradigm of our simplistic forward modelling.

\section{VALIDATION DATA SET: REPEATED LAND GRAVITY SURVEYS}

A profile of terrestrial gravity observations have been collected, before and after the earthquake, at existing geodetic marks along the east coast of New Zealand's South Island (Fig. 1a). We have used these data to assess our forward-modelled gravity changes. The marks were part of a nation-wide network of first order (vertical) geodetic marks spaced about $5 \mathrm{~km}$ apart that were surveyed during the late 1970 and $1980 \mathrm{~s}$ with the aim of monitoring long-term changes in gravity. The Marlborough and Kaikōura marks (red/black dots in Fig. 1a) were each occupied between 4 and 12 times using Lacoste and Romberg relative gravimeter D-37 in 1981 and 1986. We re-analysed the original field observations using Gsolve software (McCubbine et al. 2018a) relative to marks in western Marlborough $\left(173.1^{\circ} \mathrm{E}, 41.7^{\circ} \mathrm{S}\right)$ and North Canterbury $\left(172.7^{\circ} \mathrm{E}, 43.1^{\circ} \mathrm{S}\right)$. These have been used as reference for gravity observations made after the 2016 Kaikōura earthquake.

In 2017 and 2018, new gravity observations were acquired at all marks still assessable after the Kaikoura earthquake. Field observations were made with five different Lacoste and Romberg gravimeters (D-37, G-106, G-680, G805 and G1110) during several short campaigns. Several of the surveys coincided with absolute observations made with a MicroG FG-5 gravimeter at Seddon, Ward and Kekerengu (Fukuda et al. 2017). Due to the limited time available, the field observations concentrated on benchmarks between Blenheim and Kaikōura where most uplift occurred. The data were tied to the same marks in western Marlborough and north Canterbury used when reprocessing the 1981/1986 data. The average residual error for the processed data is $\pm .016 \mathrm{mGal}$. The differences in gravity [D $g(\mathrm{obs})]$ between the 1981/1986 data and the 2017/2018 data are shown in Fig. 2(a). A standard deviation of the residual error for each surveyed location is shown in Fig. 2(a) as two dots either side of the measured gravity change value (shown as a circle).

The agreement between the change in the measured terrestrial gravity and the forward modelled change in the surface gravity bicubically interpolated from the grid appears reasonable, having a standard deviation of \pm 0.1 (42) mGal. Fig. 2(a) shows the observed and modelled gravity and their standard deviations with respect to eq. (2). The profiles trace well together, although there are differences of up to $-0.5 \mathrm{mGal}$, which we attribute as follows.

We believe the difference between the forward-modelled and measured gravity changes are due to one more or all of: (i) the gridded deformation data being mean elevation changes over $400 \mathrm{~m}$ grid cells, whereas the gravity observations are point-wise measurements, which capture more immediate local fluctuations; (ii) a mismatch in epochs, that is the deformation model captures the topographic changes either side of the earthquake, but there may have been gravity changes from the initial observations from $1980 \mathrm{~s}$ to just before the earthquake due to other phenomena; (iii) unknown, unmodelled error in the deformation grid itself and (iv) the intrinsic 

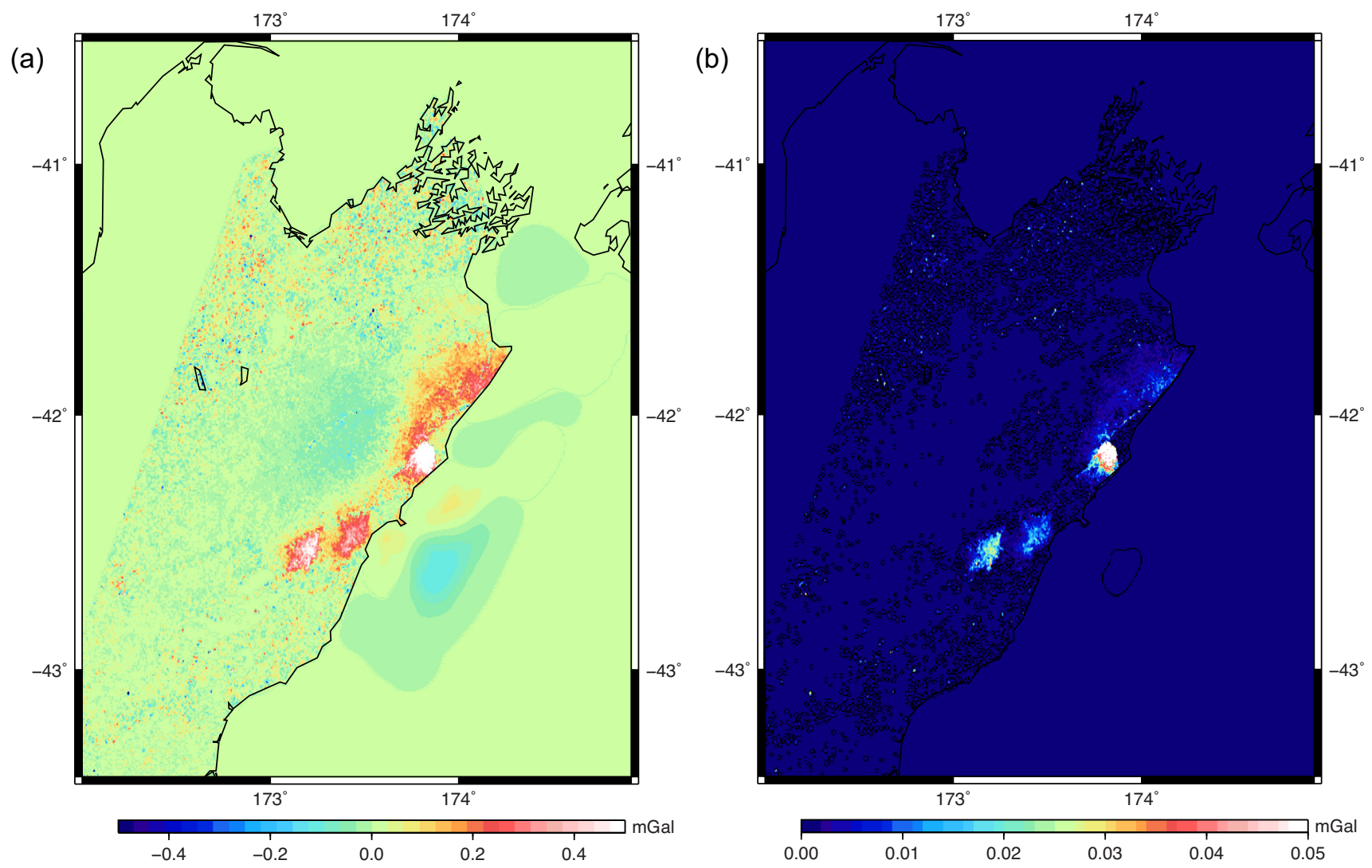

Figure 4. (a) Change in the Faye gravity anomaly, following eq. (3b). [min: -0.5 , max: 1.1, mean: $0.0(1)$, std: $0.0(5)]$ mGal. (b) STD of the feasible variations of the change of the Faye gravity anomaly with $\sigma_{\mathrm{FA}}= \pm 0.034$ and $\sigma_{\rho}= \pm 0.34$ following eq. (2). [min: 0 max: 0.4 mean: $0.0(03)$ std: $\left.0.0(16)\right] \mathrm{mGal}$.

inadequacies in the forward modelling using topographic changes alone (e.g. assumed constant density values/gravity gradients, discretization of the topography and unmodelled mass/density changes within/beneath the surface). Unfortunately, these points are not easy to investigate with the data that are available to us.

Prior to the Kaikōura earthquake, levelled height observations were made at the geodetic gravity marks for the profile shown in Fig. 1(a), these data were transformed to ellipsoidal heights using the LINZ coordinate converter (https://www.linz.govt.nz/data/ geodetic-services/coordinate-conversion/online-conversions). Following the earthquake, a subset of the marks was re-surveyed with GPS. The difference between the deformation grid and the repeat height observations are shown in Fig. 2(b). The GPS-derived height changes exhibit similar departures from the SAR derived deformation as the forward modelled and observed gravity (Fig. 2a), albeit with a change of sign. This indicates that the differences between the measured and forward modelled gravity values are largely attributable to the qualifiers (i), (ii) and (iii) mentioned above.

\section{MODELLING CHANGES IN THE QUASI GEOID}

\subsection{Direct forward modelling of the quasigeoid}

Given a right-rectangular prism of some assumed-constant bulk density $\rho$, Nagy et al. (2000) provide the formulas to evaluate the resulting potential field, $V$. We have used this formula to compute the potential field, $V$ resulting from the vertical deformation model with uniform densities values of $\rho=2670 \mathrm{~kg} \mathrm{~m}^{-3}$ onshore and $\rho=1670 \mathrm{~kg} \mathrm{~m}^{-3}$ offshore. The change in the quasigeoid height, $\mathrm{D} \zeta$, is given by Bruns's formula, that is the change in the potential field $V$ divided by normal gravity, $\gamma$, computed at the corresponding point on the telluroid (e.g. Moritz 1980). The quasigeoid height change is shown in Fig. 3 and has a maximum of $+6 \mathrm{~mm}$.

Similarly to the gravitational acceleration effect, the integration to obtain potential field values was computed with respect to the effect and sum of all 490000 right-rectangular prisms at each point of the grid. However, on comparison to the prism formula to determine gravity (Nagy 1966) the formula for the potential instead involved the evaluation of twice as many terms per prism (48 rather than 24), thus doubling the computation time.

\subsection{Modified Stokes's integration}

NZGeoid2017 (McCubbine et al. 2018b) was computed by a Wong \& Gore (1969) modified Stokes's integration of surface Faye gravity anomalies with the remove-compute-restore technique using the EGM2008 (Pavlis et al. 2012, 2013) global geopotential model. Free-air gravity anomalies were determined by interpolating point-wise Bouguer gravity anomalies at regular grid points, then restoring the effect of topography using a 'reverse' Bouguer slab (Featherstone \& Kirby 2000), applied with a constant density of $\rho=2670 \mathrm{~kg} \mathrm{~m}^{-3}$. Heights for the Bouguer slab were determined from a DEM. Faye gravity anomalies, as approximations of Molodensky gravity anomalies on the topography, were computed by adding high-resolution planar terrain corrections. 
(a)

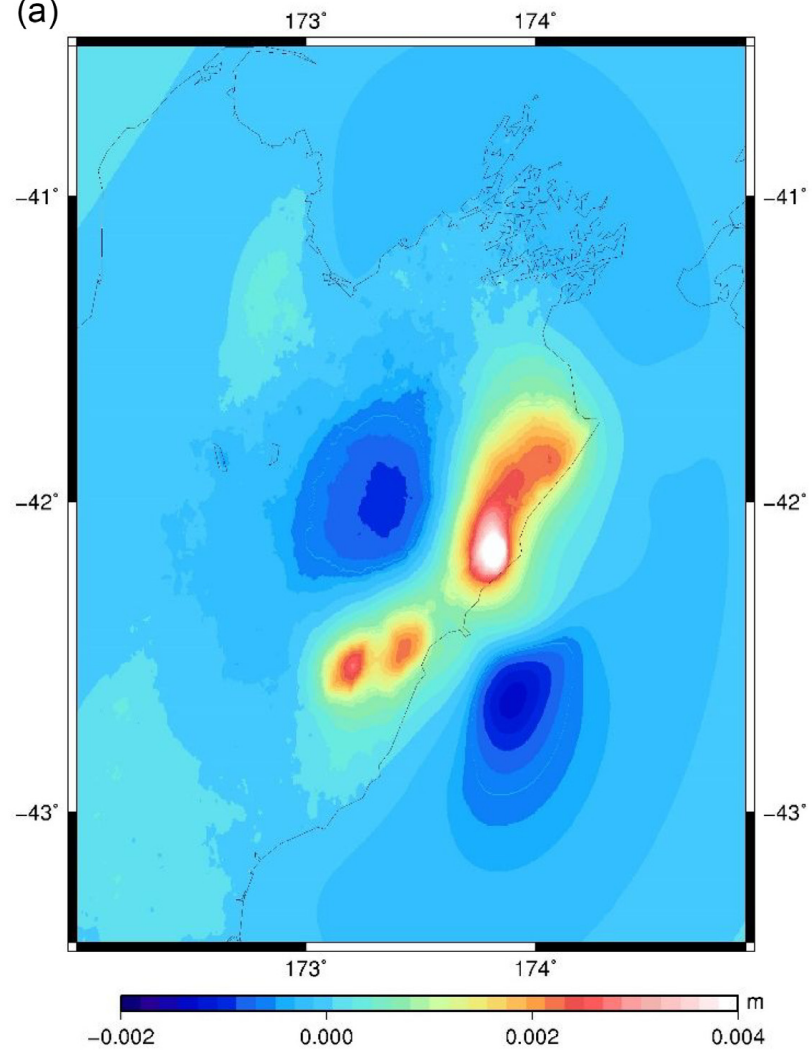

(b)

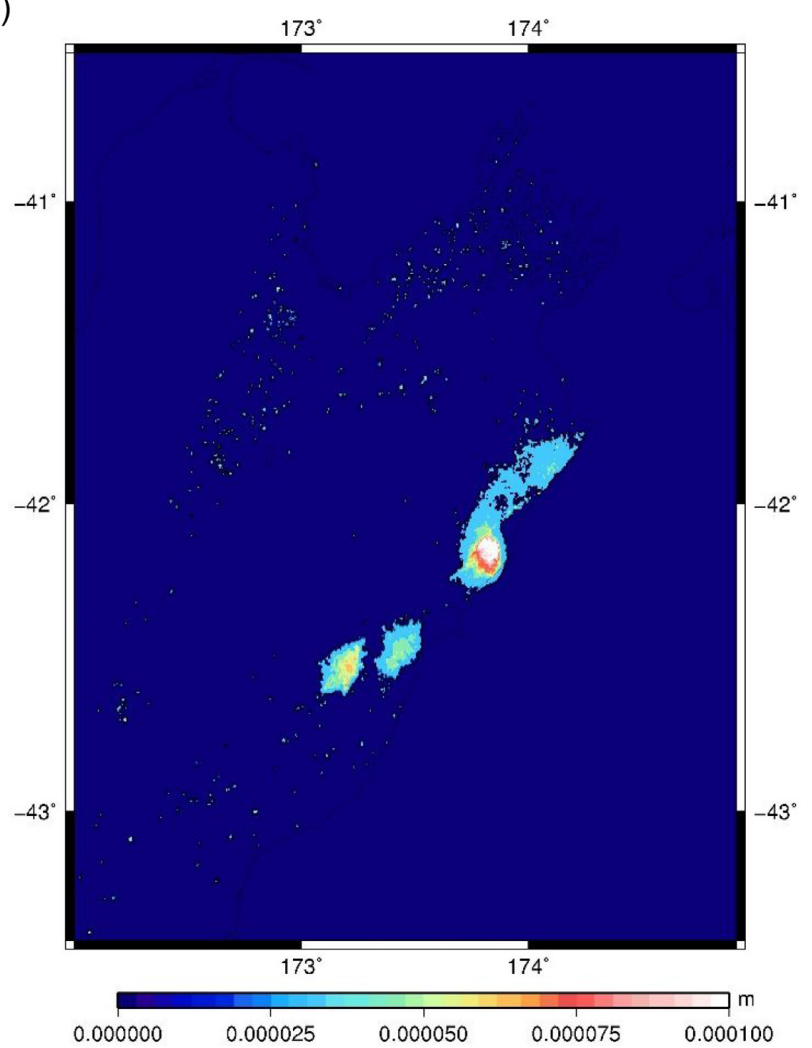

Figure 5. (a) Change in the Wong-Gore modified Stokesian quasigeoid due to the vertical deformation caused by the 2016 Kaikōura earthquake with gravity changes synthesized by eq. (3b). [min: -1 , max: 5, mean: 0.1 , std: 1] mm. (b) Propagated effects of the feasible Faye gravity anomaly change variations into the quasigeoid. [min: 0.0, max: 0.1, mean: 0.0 , std: $0.0(05)] \mathrm{mm}$.

Within this framework, the gravity response, $\Delta g_{\text {Faye }}$, to the vertical deformation model is modelled by the addition of (i) the topographic effect due to the mass prisms offshore, $\left.\Delta g_{\text {Topo }}(\rho)\right|_{\text {offshore }}$ and (ii) the additional contribution to the Bouguer slab for all height changes onshore, $\left.0.0419 \rho \Delta H\right|_{\text {onshore }}$. This can be formulated in a simple way by the cancelation between terms in eq. (1) when applying the free air correction and planar gravimetric terrain corrections (given by eq. 3a).

$$
\begin{aligned}
\Delta g_{\mathrm{TC}}(\rho) \approx & \left.0.0419 \rho \Delta H\right|_{\text {onshore }}-\Delta g_{\text {Topo }}(\rho) \\
& +\left.\Delta g_{\text {Topo }}(\rho)\right|_{\text {offshore }}
\end{aligned}
$$

$\left.\Delta g_{\text {Faye }} \approx 0.0419 \rho \Delta H\right|_{\text {onshore }}+\left.\Delta g_{\text {Topo }}(\rho)\right|_{\text {offshore }}$

Fig. 4(a) shows the expected change in the Faye gravity anomaly using the vertical deformation observations and eq. (3b). The bulk density values are the same as used in eq. (1). The gravity anomaly changes have a minimum of $-0.5 \mathrm{mGal}$ and a maximum of $+1.1 \mathrm{mGal}$. The changes are mostly dominated by the Bouguer slab effect, although the Newtonian integration of bathymetric changes offshore lead to gravitational changes of up to $0.1 \mathrm{mGal}$. Standard deviations of the modelled Faye gravity anomaly changes due to variations in the assumed-constant free air gradient and topographic density are also captured by eq. (2) (Fig. 4b).

The change in Faye gravity anomalies (Fig. 4a) was Stokesintegrated to give the corresponding quasigeoid height changes due to the earthquake (Fig. 5a). We used the same integration parameters as used for NZGeoid2017 (McCubbine et al. 2018b), that is a degree-160 Wong \& Gore (1969) modified Stokes's integral over a spherical cap radius of $2.5^{\circ}$. The maximum quasigeoid change is $+5 \mathrm{~mm}$ and is centred at the point where the most land uplift occurred. These results demonstrate how the quasigeoid model might have changed had an alternative 'deformed' DEM been used to recover the Faye gravity anomaly from the interpolated Bouguer gravity anomaly values.

Standard deviation estimates of the forward modelled Faye gravity anomaly changes, by eq. (2), (Fig. 4b) have also been propagated through the modified Stokes's integral (following the methodology given by Featherstone et al. (2018) but here for the Wong-Gore kernel). They have a maximum of $+0.1 \mathrm{~mm}$, again centred at the location of the most topographic change. These are relatively small in comparison to the predicted quasigeoid changes, which indicates that the modelled quasigeoid change is reasonably insensitive to variations in the assumptions made of uniform density and vertical gravity gradient.

\subsection{Unmodified (spherical) Stokes's integration}

Modified Stokes kernels in conjunction with the remove-compute restore procedure for regional quasigeoid solutions can deliver better agreements with independent GPS-levelling data, for example from empirical tests in New Zealand (McCubbine et al. 2018b) and elsewhere [too many to cite here]. This is due to the reduction of long-wavelength terrestrial gravity data errors that are not present in a vertical deformation model. If one wishes to determine a 'correction' to a gravimetric quasigeoid model as we have done here, one should choose to use an unmodified kernel over a large integration 

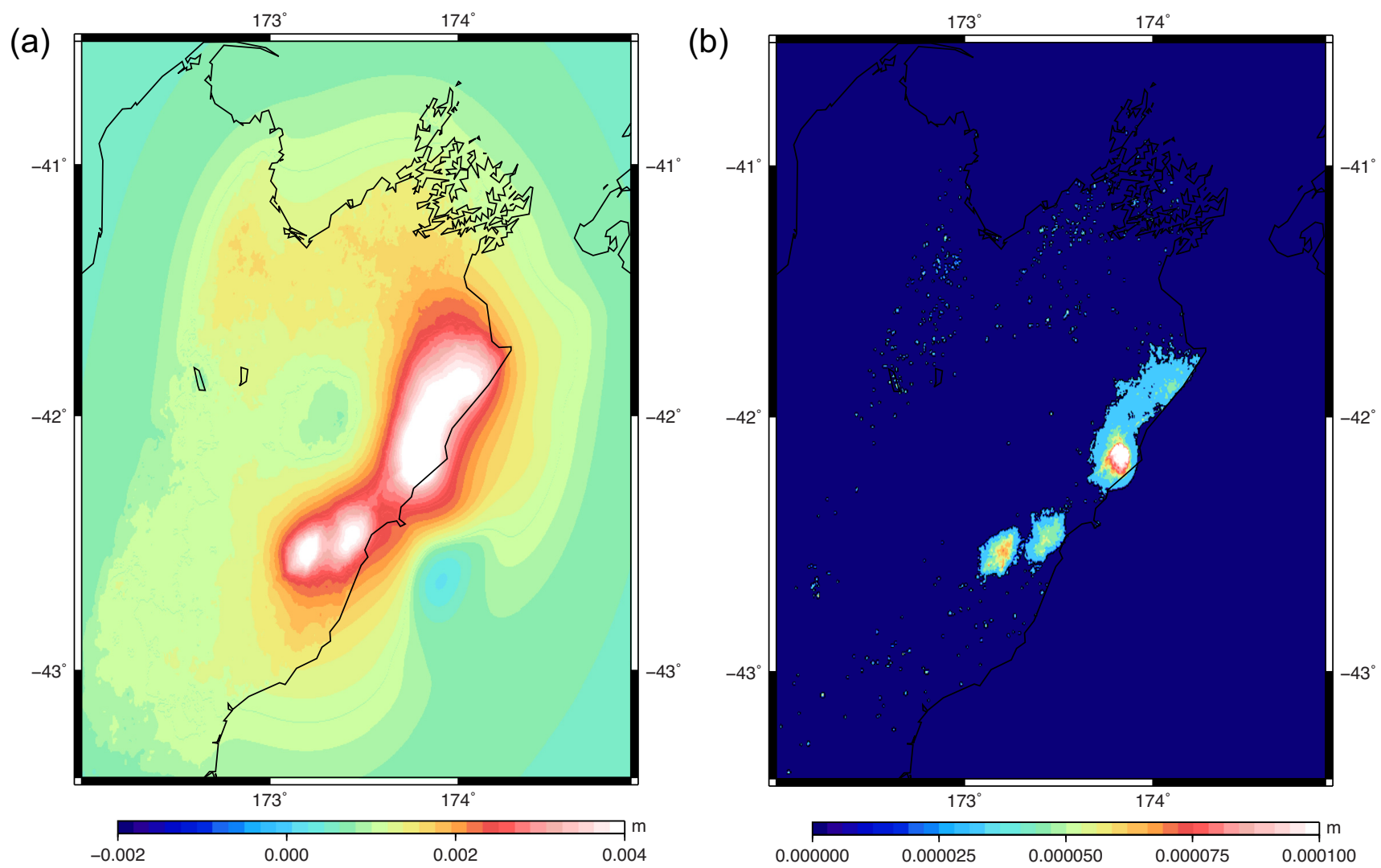

Figure 6. (a) Change in the quasigeoid over the Kaikōura region with gravity changes synthesized by eq. (3b) integrated using an unmodified spherical Stokes's kernel. [min: 0, max: 7, mean: 1, std: 0.6] mm (b) Propagated effects of the feasible Faye gravity anomaly change variations into the quasigeoid integrated using an unmodified Stokes's kernel. [min: 0, max: 0.(1), mean: 0, std: 0.(006)] mm.

cap even if the underlying quasigeoid may have used a modified kernel and smaller cap.

For this reason we also performed Stokes's integration of the estimated change in the Faye gravity anomaly (Fig. 4a) with an unmodified [spherical] kernel. The cap radius was increased to $10^{\circ}$ so that the quasigeoid change was affected by all modelled changes to the Faye gravity anomalies. This is equivalent to a global integration, so there is no truncation bias, as there are no gravitational effects outside the deformation zone that contribute to the quasigeoid change. The results are given in Fig. 6(a) and have a maximum of $+7 \mathrm{~mm}$. As before, the standard deviations were also propagated through Stokes integral (following the methodology given by Featherstone et al. (2018) but here for the spherical Stokes kernel) and are shown in Fig. 6(b).

Similarly to the results of the so-called direct approach (Section 4.1), the quasigeoid features from the unmodified Stokes kernel are broader in scale and larger in magnitude on comparison to the truncated Wong-Gore modified kernel ( $c f$. Figs 3, 5a and 6a). This is within expectation since long-wavelength features are partially filtered from the quasigeoid using the modified Stokes's integration, whereas the unmodified spherical Stokes is not a filter when applied globally ( $c f$. Vaníček \& Featherstone 1998). Likewise, the so-called direct method, via the Nagy et al. (2000) prism formula, to compute the quasigeoid change resulting from the vertical deformation does not perform any high pass filtering of the gravity/quasigeoid signal. The difference between the direct approach and unmodified Stokes's integral are shown in Fig. 7. In Fig. 7, there appears to be some Gibbs fringing artefacts. These are likely to be attributable to the discrete Fourier transform methods applied to solve a global Stokes convolution integral (Fig. 6) over a limited integration domain. They are not present to the Nagy prism method (Fig. 3) and so appear in the plotted differences.

\section{STATISTICAL [IN]SIGNIFICANCEOF THE MODELLED QUASIGEOID CHA NGES}

The precision of the NZGeoid2017 model was assessed externally by comparison to GPS-levelling quasigeoid heights (McCubbine et al. 2018b). Over the Kaikōura region, there are 170 GPS-levelling data points. The 170 quasigeoid/GPS-levelling residuals had a zero mean after the removal of local vertical datum offsets [following the methodology of Amos \& Featherstone (2009)] and a standard deviation of $\pm 58 \mathrm{~mm}$. Figs 8 (a) and (b) show the NZGeoid2017 model over the Kaikōura region and NZGeoid2017/GPS-levelling residuals.

The largest modelled changes in the quasigeoid due to the vertical deformation were given by unmodified spherical Stokes integration (Fig. 6a). We have added these modelled quasigeoid changes to NZGeoid2017 to produce an 'updated quasigeoid' model, which is 'deformed' to account for the gravitational effect of the vertical deformation.

The 'updated quasigeoid' model/GPS-levelling residuals have a mean of $+0 .(03) \mathrm{mm}$ (without adjusting the applied local vertical datum offsets) and a standard deviation of $\pm 57 \mathrm{~mm}$. An $F$-test (with the test statistic $\frac{\sigma_{1}^{2}}{\sigma_{2}^{2}}=\frac{57.7^{2}}{58.6^{2}}$ and 169 degrees of freedom (e.g. Snedecor \& Cochran 1989) shows that the difference between 


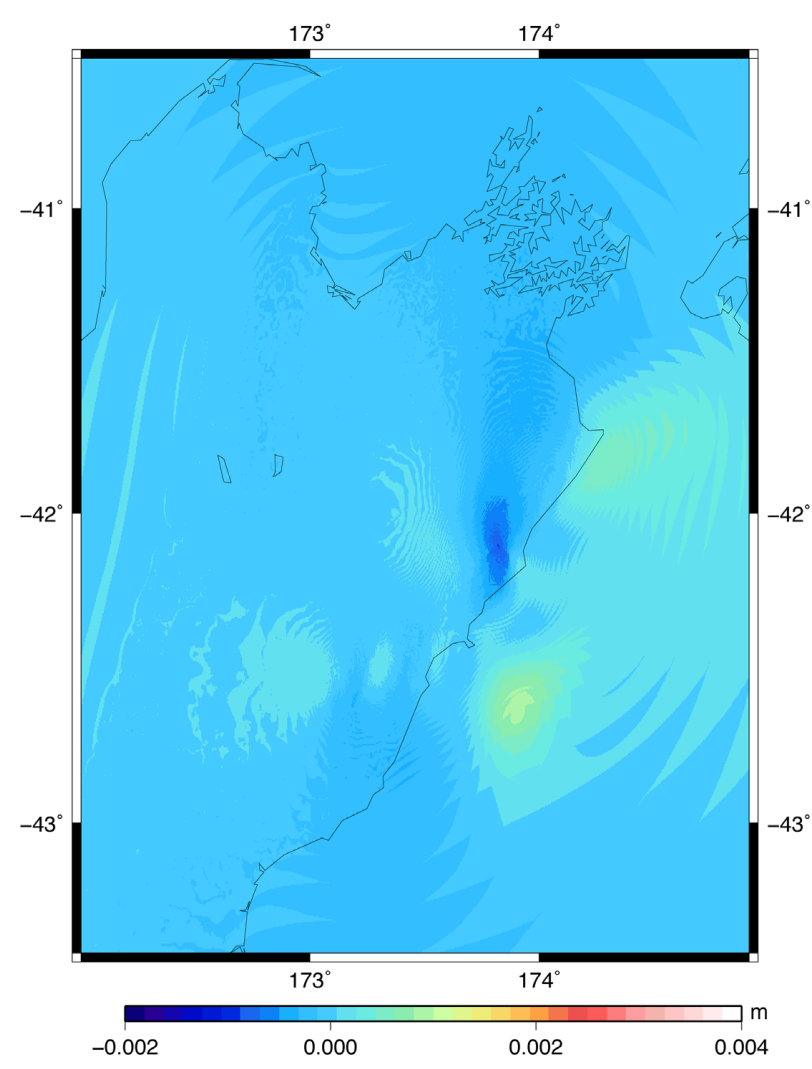

Figure 7. Difference between Nagy et al. (2000) prism formula quasigeoid change and unmodified Stokes integral of forward modelled changes in the Faye gravity anomaly [min: -1 , max: 1, mean: -0.(003), std: $0 .(2)] \mathrm{mm}$.

the quasigeoid/GPS-levelling residuals of both the NZGeoid2017 model and the updated model is not statistically significant at the 95 per cent confidence level. Furthermore, the largest standard deviation value in Fig. $6 \mathrm{~b}$ has a value of \pm 0 .(1) $\mathrm{mm}$. This indicates the quasigeoid change could be a further $0.4 \mathrm{~mm}$ different (at the three sigma level) at the point of the maximum had the choice of uniform density and free air gradient been different. As a worse-case scenario, even adding random variables with the maximum $0.1 \mathrm{~mm}$ standard deviation to the all of the residuals, the change in the propagated variance is still statistically insignificant.

\section{FURTHER DISCUSSION}

The forward-modelled change in the gravitational signal and corresponding variations due to assumptions about the topographic bulk density and vertical gravity gradient have been compared to some repeat terrestrial gravity observations along a profile of geodetic gravity observations. The differences between the modelled change in the gravitational signal and the repeat terrestrial gravity observations have a standard deviation of $\pm 0.1(42) \mathrm{mGal}$. The modelled and observed gravity signal differences largely seem to mirror differences between observed GPS height changes and the SAR-derived vertical deformation model. This indicates that inaccuracies in the modelled gravity data are largely attributable to inaccuracies in the SAR-derived vertical deformation model rather than intrinsic deficiencies in the forward modelling approach, at least along this profile. However, we feel that this needs further investigation with a larger set of repeat gravity observations, in particular to assess the effect of neglecting subsurface bulk density changes.

We have modelled the corresponding change in the quasigeoid over the Kaikōura region via three methods: (i) directly forward modelling the potential gravity field due to the changed in topography from the vertical deformation model and dividing by normal gravity on the telluroid to produce the quasigeoid change; (ii) using the vertical deformation model to compute the change in the Faye gravity anomaly and propagating the change through the same modified Stokes integral as was used to compute NZGeoid2017 and (iii) propagating the modelled changes in the Faye gravity anomaly through an unmodified Stokes integral. Following the broad classification in the Introduction, method (i) is akin to the remove-compute restore approach based on a DEM. Methods (ii) and (iii) are akin to the 'classical' Stokesian integration of gravity anomalies.

Method (i) evaluates the contribution of the vertical deformation to the potential gravity field and subsequently the quasigeoid by Newtonian integration of the prisms in the vertical deformation model. The largest quasigeoid change modelled by this method was $+6 \mathrm{~mm}$. Like method (iii), no [partial] high-pass filtering of the gravity signal is performed. For this reason, the results of methods (i) and (iii) match more closely than the results of method (ii), particularly with respect to longer wavelength features [e.g. the difference between the means $=-0 .(003) \mathrm{mm}$.

The treatment of the topographic gravitational effect via method (i) differs from the other two. For methods (ii) and (iii), the quasigeoid is determined by Stokesian integration of the Faye gravity anomaly, where the gravitational effect of the topography is replaced by that of a Bouguer slab. Whereas using method (i), the effect of missing masses below and additional masses above each computation point are preserved. Therefore, some differences in the quasigeoid's change computed by the differing methods are to be expected, as shown in Fig. 7.

The agreement between 170 GPS-levelling quasigeoid heights and the NZGeoid2017 model did not appear to be adversely affected by including the largest amplitude quasigeoid changes modelled via method (iii). The change in the residuals is not evident visually or statistically. This demonstrates that the effect of the vertical deformation on the quasigeoid model is not appreciable, at least given the underlying precision of the NZGeoid2017 model, the GPS-levelling data and the way the quasigeoid response has been modelled.

\section{SUMMARY AND CONCLUSION}

National vertical datums that use an assumed-static regional quasigeoid model as a reference surface rely upon its temporal stability. However, topographic changes have a strong correlation with changes in the surface gravity field, from which quasigeoid models are modelled. Temporal changes in the topography can be measured reasonably easily and freely using SAR/InSAR techniques. We have shown here that, with some underlying assumptions regarding topographic bulk density and vertical gravity gradient, these data can be used to produce an initial assessment of the surface gravity and quasigeoid response to topographic changes. This is pertinent for large magnitude (earthquakes) or ongoing topographic deformation (high-rate subsidence or uplift), where the spatial scale of the topographic changes may be too short a 

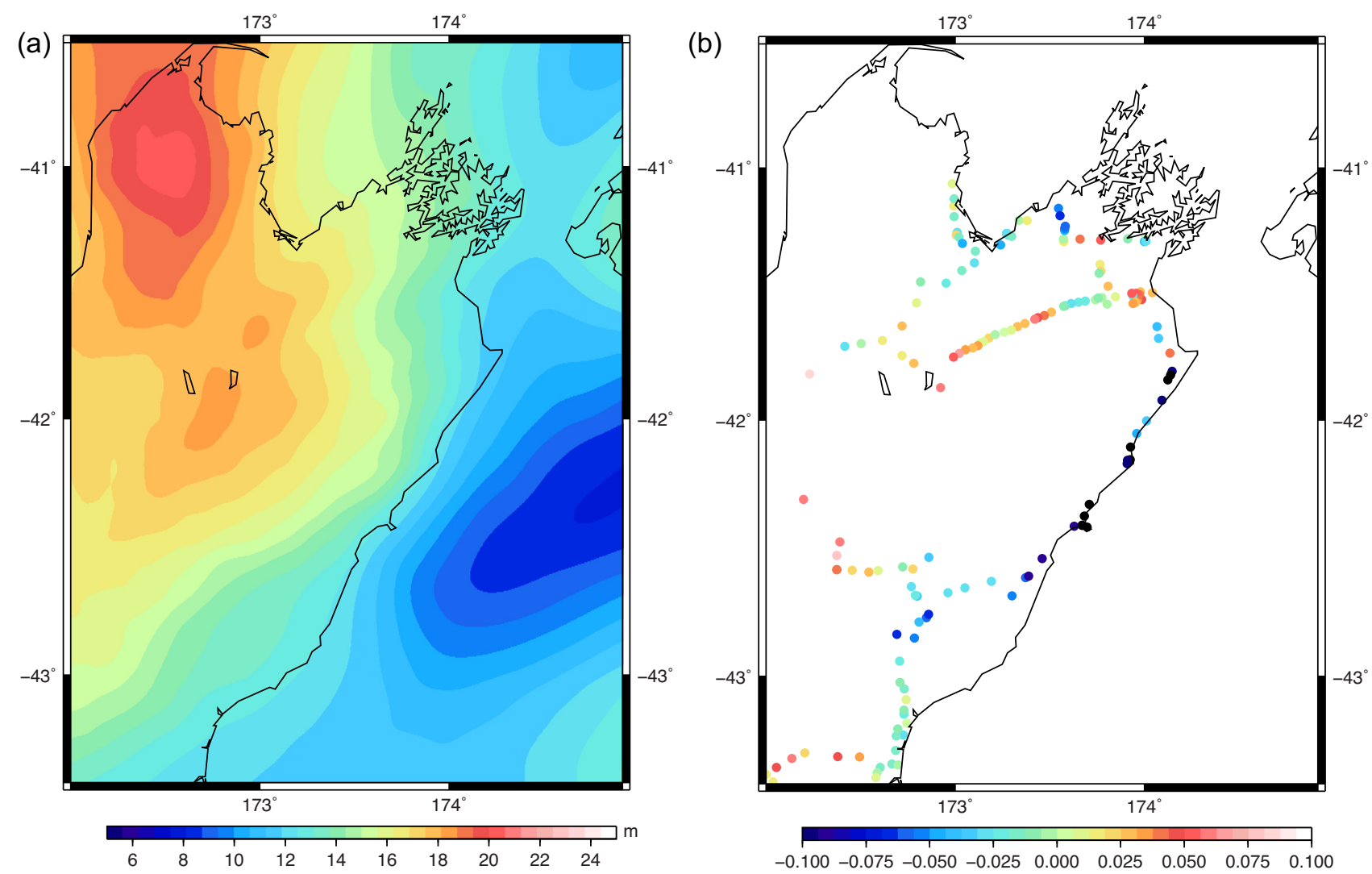

Figure 8. (a) NZGeoid2017 of the study region [min: 8.05, max: 20.31, mean:14.15, std: 3.10] m. (b) 170 GPS-levelling derived quasigeoid height valuesNZGeoid2017 [min: -163.2, max: 170.9, mean: 0, std: 57.7] mm.

wavelength to be captured by satellite gravimetry and in circumstances where it is not feasible to collect new terrestrial gravity observations.

Over New Zealand's Kaikōura region, a 10-100-km-scale crustal deformation event occurred due to the 2016 Kaikoura $7.8 M_{\mathrm{w}}$ earthquake. We have forward modelled a SAR-derived vertical displacement field into gravitational acceleration and quasigeoid changes. The largest modelled change in the surface gravity is approximately $+2.9(19) \mathrm{mGal}$ with a nominal accuracy of $\pm 0.1(42) \mathrm{mGal}$ on comparison to a profile of repeated terrestrial gravity observations. The largest quasigeoid changes were $\sim 6 \mathrm{~mm}$ for the so-called direct method, $\sim 5 \mathrm{~mm}$ for the same modified Stokes kernel method used for NZGeoid2017, and $\sim 7 \mathrm{~mm}$ for an unmodified [spherical] Stokes kernel. We were not able to fully validate the modelled quasigeoid changes with GPS levelling, although 5-7 $\mathrm{mm}$ is an order of magnitude smaller than the $58 \mathrm{~mm}$ nominal precision of NZGeoid2017. For this reason, we believe it would not be appropriate to amalgamate these quasigeoid changes into the current gravimetric quasigeoid.

\section{ACKNOWLEDGEMENTS}

This work has been supported financially by the Cooperative Research Centre for Spatial Information, whose activities were funded by the Business Cooperative Research Centres Programme, Land Information New Zealand and by Geoscience Australia. The work was also supported by GNS Science, Kyoto University, Japan
Aerospace Exploration Agency and Kyushu University. Jack McCubbine, Matthew Garthwaite and Nicholas Brown publish this paper with the permission of the Chief Executive Officer of Geoscience Australia. Maps and charts in this paper were produced using GMT (Wessel et al. 2013). We would like to thank the handling editor (Prof Vermeersen) and the reviewers (Jerome Verdun and one anonymous) for their contributions to improving this manuscript.

\section{REFEREN CES}

Amante, C. \& Eakins, B.W., 2009. ETOPO1 arc-minute global relief model: procedures, data sources and analysis, NOAA Technical Memorandum NESDIS NGDC-24.

Amos, M. \& Featherstone, W., 2009. Unification of New Zealand's local vertical datums: iterative gravimetric quasigeoid computations, J. Geod., 83(1), 57-68.

Chen, J., Wilson, C., Tapley, B. \& Grand, S., 2007. GRACE detects coseismic and postseismic deformation from the Sumatra-Andaman earthquake, Geophys. Res. Lett., 34(13), doi:10.1029/2007GL030356.

Featherstone, McCubbine, J., Brown, N., Claessens, S., Filmer, M. \& Kirby, J., 2018. The first Australian gravimetric quasigeoid model with locationspecific uncertainty estimates, J. Geod., 92(2), 149-168.

Featherstone, W.E. \& Kirby, J.F., 2000. The reduction of ailiasing in gravity anomalies and geoid heights using digital terrain data, Geophys. J. Int., 141(1), 204-212. https://doi.org/10.1046/j.1365-246X.2000.00082.x.

Forsberg, R., 1984, A study of Terrain reductions, density anomalies and geophysical inversion methods in gravity field modelling rep., Ohio State Univ Columbus Dept Of Geodetic Science and Surveying.

Forsberg, R., 1993. Modelling the fine-structure of the geoid: methods, data requirements and some results, Surv. Geophys., 14(4-5), 403-418. 
Fukuda, Y. et al., 2017. New absolute gravity measurements in New Zealand, IAG SYMPOSIA, 148, doi:10.1007/1345_2017_18.

Garcia, A. \& Funning, G.J., 2018. A systematic study of earthquake detectability using Sentinel-1 Interferometric Wide-Swath data, Geophys. $J$. Int., 216(1), 332-349.

Gusman, A.R., Satake, K., Gunawan, E., Hamling, I. \& Power, W., 2018. Contribution from multiple fault ruptures to tsunami generation during the 2016 kaikoura Earthquake, Pure appl. Geophys., 175(8), 2557-2574.

Hamling, I.J. et al., 2017. Complex multifault rupture during the $2016 \mathrm{Mw}$ 7.8 Kaikōura earthquake, New Zealand, Science, 356(6334), eaam7194, doi:10.1126/science.aam7194.

Hatherton, T. \& Leopard, A.E., 1964. The densities of New Zealand rocks, New Zealand, J. Geol. Geophys., 7(3), 605-625.

Hirt, C., Featherstone, W. \& Marti, U., 2010. Combining EGM2008 and SRTM/DTM2006. 0 residual terrain model data to improve quasigeoid computations in mountainous areas devoid of gravity data, J. Geod., 84(9), 557-567.

Li, Y. \& Sideris, M., 1994. Improved gravimetric terrain corrections, Geophys. J. Int., 119(3), 740-752.

Lindsey, E.O., Natsuaki, R., Xu, X., Shimada, M., Hashimoto, M., Melgar, D. \& Sandwell, D.T., 2015. Line-of-sight displacement from ALOS-2 interferometry: Mw 7.8 Gorkha Earthquake and Mw 7.3 aftershock, Geophys. Res. Lett., 42(16), 6655-6661.

McCubbine, J., Caratori Tontini, F., Stagpoole, V., Smith, E. \& O’Brien, G., 2018a. Gsolve, a Python computer program with a graphical user interface to transform relative gravity survey measurements to absolute gravity values and gravity anomalies, SoftwareX, 7, 129-137.

McCubbine, J.C., Amos, M.J., Caratori Tontini, F., Smith, E., Winefied, R., Stagpoole, V. \& Featherstone, W.E., 2018b. The New Zealand gravimetric quasigeoid model 2017 that incorporates nationwide airborne gravimetry, J. Geod., 92(8), 923-937.

McCubbine, J., Featherstone, W. \& Brown, N., 2018c. Error propagation for the Molodensky G1 term. J. Geod., 93(6), 889-898.

Moritz, H., 1980. Advanced physical geodesy, EOS, Trans. Am. Geophys. Un., 63(21), 514, doi:10.1029/EO063i021p00514-03.
Nagy, D., 1966. The gravitational attraction of a right rectangular prism, Geophysics, 31(2), 362-371.

Nagy, D., Papp, G. \& Benedek, J., 2000. The gravitational potential and its derivatives for the prism, J. Geod., 74(7-8), $552-560$.

Pavlis, N.K., Holmes, S.A., Kenyon, S.C. \& Factor, J.K., 2012. The development and evaluation of the Earth Gravitatonal Model 2008 (EGM2008) J. Geophys. Res. Solid Earth, 117(B4), B04406. https://doi.org/10.1029/2011JB008916(8):B04406.

Pavlis, N.K., Holmes, S.A., Kenyon, S.C. \& Factor, J.K., 2013. Correciton to: The development and evaluation of the Earth Gravitatonal Model 2008 (EGM2008), J. Geophys. Res. Solid Earth, 118(5), 2633. https://doi.org/10.1029/jgrb.50167.

Rexer, M., Hirt, C., Bucha, B. \& Holmes, S., 2018. Solution to the spectral filter problem of residual terrain modelling (RTM), J. Geod., 92(6), 675-690.

Sansò, F. \& Sideris, M.G., 2013. Geoid Determination: Theory and Methods, Springer Science \& Business Media.

Snedecor, G.W. \& Cochran, W.G., 1989. Statistical Methods, 8th edn, Iowa State University Press.

Tapley, B.D., Bettadpur, S., Ries, J.C., Thompson, P.F. \& Watkins, M.M., 2004. GRACE measurements of mass variability in the Earth system, Science, 305(5683), 503-505.

Torres, R. et al., 2012. GMES Sentinel-1 mission, Rem. Sens. Environ., 120, 9-24.

Vaníček, P. \& Featherstone, W., 1998. Performance of three types of Stokes's kernel in the combined solution for the geoid, J. Geod., 72(12), 684-697.

Wessel, P., Smith, W.H., Scharroo, R., Luis, J. \& Wobbe, F., 2013. Generic mapping tools: improved version released, EOS, Trans. Am. Geophys. Un., 94(45), 409-410.

Wong, L. \& Gore, R., 1969. Accuracy of geoid heights from modified Stokes kernels, Geophys. J. Int., 18(1), 81-91.

Zhou, X., Zhong, B. \& Li, X., 1990. Gravimetric terrain corrections by triangular-element method, Geophysics, 55(2), 232-238. 